\title{
Quais os limites à intervenção estatal legítima?
}

\section{What are the limits to legitimate state intervention?}

Um dos assuntos mais recorrentes no âmbito do Direito Público consiste na identificação, dentro de cada contexto social e estatal específico, dos limites à intervenção legítima do Poder Público na vida privada, na autonomia dos indivíduos e na definição de uma concepção de vida boa para toda a sociedade. Até que ponto o Estado deve assumir para si tarefas que dizem respeito à vida dos cidadãos? Quando poderá realizar escolhas morais e, por meio da criação de leis, estabelecê-las como um padrão a ser seguido por toda a cidadania? Pode o Estado proibir o aborto - ou, como preferem alguns, a interrupção da gestão - e com isso interferir diretamente no corpo da mulher, em nome da proteção da vida do nascituro? Está o Poder Público autorizado a vedar o uso de véu, tradicional em algumas religiões, em escolas públicas? Esses são temas enfrentados nos três primeiros estudos desta edição, a partir das perspectivas estadunidense e egípcia.

De outro lado, qual é o papel do Poder Judiciário e dos outros órgãos de fiscalização no que diz respeito ao controle de conformidade das leis e atos normativos com a Constituição e com os tratados internacionais? Até que ponto essas instâncias, compostas por mecanismos estatais institucionais, estão legitimadas a interferir na autonomia pública do povo e rever decisões tomadas em espaços de deliberação democrática, em nome da tutela da supremacia constitucional ou convencional? São as reflexões

Como citar este editorial | How to cite this editorial: HACHEM, Daniel Wunder. Editorial: Quais os limites à intervenção estatal legítima? Revista de Investigações Constitucionais, Curitiba, vol. 4, n. 1, p. 6-9, jan./abr. 2017. DOI:10.5380/rinc.v4i1.50653 
apresentadas no quarto e quinto artigos deste número, sob os pontos de vista cubano e brasileiro.

E além dos limites à intervenção do Poder Legislativo e do Poder Judiciário, qual seria o papel da Administração Pública e da justiça administrativa nos dias atuais? Diante das mudanças relativas aos modelos de Estado, quais foram as transformações experimentadas pela Administração Pública? E quais são os desafios da jurisdição administrativa no controle dos atos e omissões administrativas nos ordenamentos jurídicos contemporâneos? Tais temáticas são objeto de análise do sexto, sétimo e oitavo artigos do presente fascículo, sob o prisma dos sistemas latino-americano, estadunidense, britânico, australiano, chinês, argentino e japonês.

Finalmente, até que ponto pode o órgão legitimado para modificar a Constituição - e exercer o chamado "poder de reforma" - engessar os gastos públicos pelo prazo de 20 anos, afetando com isso investimentos em políticas públicas e serviços públicos relevantíssimos para o desenvolvimento humano, tais como saúde e educação? Quais os aspectos relativos à autonomia financeira e orçamentária, bem como à separação dos poderes, exigem maior reflexão, num cenário em que uma emenda constitucional dessa natureza foi promulgada e teve a sua constitucionalidade questionada perante o Supremo Tribunal Federal? Esse assunto é estudado às minúcias, sob vieses distintos, pelos dois artigos que encerram esta edição.

Neste número da Revista de Investigações Constitucionais que inaugura o volume de 2017, publicamos artigos em 3 idiomas (inglês, espanhol e português), de autores vinculados a 10 instituições de ensino superior de 4 países diferentes (Estados Unidos da América, Egito, Cuba e diferentes Estados-membros da República Federativa do Brasil - Minas Gerais, Rio de Janeiro, Ceará e Rio Grande do Sul). Dos trabalhos publicados, $80 \%$ são de Professores Doutores, 40\% redigidos em língua estrangeira, 50\% dos artigos são de autores estrangeiros e $100 \%$ dos autores são exógenos ao Estado do Paraná. São eles:

- Abortion Once Again: a response to Feser, Goodwin, Mosquito, Sadowsky, Vance and Watkins

\section{Walter E. Block}

Harold E. Wirth Eminent Scholar Endowed Chair in Economics at Loyola University College of Business (Chicago, United States of America)

- Reproductive Healthcare Services and the U.S. Supreme Court: Beyond Roe v. Wade and "Abortion Clinics"

\section{Karla A. Vergara Pérez}

Juris Doctor - J.D. Candidate (2017) at Boston College Law School (Boston, United States of America) 
- The prohibition of wearing veil in public schools in Egypt: an analysis of the Egyptian Supreme Constitutional Court jurisprudence

\section{Mohamed A. 'Arafa}

Adjunct Professor of Islamic Law at Indiana University Robert H. McKinney School of Law (Indianapolis, United States of America)

- Los mecanismos de control constitucional: un análisis desde y para Cuba con especial referencia a la inconstitucionalidad por omisión

\section{Raudiel F. Peña Barrios}

Profesor de Derecho Constitucional en el Departamento de Estudios Jurídicos Básicos de la Facultad de Derecho de la Universidad de La Habana (La Habana, Cuba)

- O controle de convencionalidade e o Judiciário brasileiro: a sua aplicação pelo Tribunal Superior do Trabalho como forma de proteger a dignidade da mãode-obra (vedação de terceirização de atividade-fim) no case Carneiro Távora v. Telemar Norte Leste e Contax

\section{Mônia Clarissa Hennig Leal}

Professora e Coordenadora Adjunta do Programa de Pós-Graduação em Direito (Mestrado e Doutorado) da Universidade de Santa Cruz do Sul - UNISC (Santa Cruz do Sul-RS - Brasil)

\section{Felipe Dalenogare Alves}

Professor Adjunto na graduação em Direito da Faculdade Antonio Meneghetti (Restinga Sêca-RS, Brasil)

- Cinco modelos de adjudicação administrativa (Justiça Administrativa)

\section{Michael Asimow}

Visiting Professor of Law na Stanford Law School (Stanford, Estados Unidos da América)

- Desafios contemporâneos da justiça administrativa na América Latina

\section{Ricardo Perlingeiro}

Professor Titular da Faculdade de Direito da Universidade Federal Fluminense (Niterói-RJ, Brasil)

- Transformações do Estado e a Administração Pública no século XXI

\section{Eurico Bitencourt Neto}

Professor Adjunto de Direito Administrativo e Direito Constitucional da UFMG (Belo Horizonte-MG, Brasil) 
- Novo Regime Fiscal, autonomia financeira e separação de poderes: uma leitura em favor de sua constitucionalidade

Vanice Regina Lírio do Valle

Professora Permanente do PPGD da Universidade Estácio de Sá - UNESA (Rio de Janeiro-RJ, Brasil)

- Emenda constitucional 95/2016 e o teto dos gatos públicos: Brasil de volta ao estado de exceção econômico e ao capitalismo do desastre

\section{Cynara Monteiro Mariano}

Professora Adjunta da Faculdade de Direito da Universidade Federal do Ceará (Fortaleza-CE, Brasil)

As ideias lançadas a debate pelas excelentes pesquisas condensadas nesta edição contribuirão para o aperfeiçoamento do Direito Público contemporâneo, especialmente em razão da apresentação de posicionamentos plurais e muitas vezes divergentes, em uma contraposição de argumentos certamente fundamental para o aprimoramento científico.

Curitiba, janeiro de 2017.

\section{Prof. Dr. Daniel Wunder Hachem}

Coordenador Editorial da Revista de Investigações Constitucionais 